\title{
Balancing the critical period of spiking neurons with attractor-less STDP
}

\author{
Simon M Vogt ${ }^{1 *}$, Ulrich G Hofmann ${ }^{2}$ \\ From 24th Annual Computational Neuroscience Meeting: CNS*2015 \\ Prague, Czech Republic. 18-23 July 2015
}

Attractor-based ("multiplicative") STDP has been called a biologically more realistic form of spike timing dependent plasticity than attractor-less ("additive") variants [1-4], as it produces unimodal distributions of synaptic weights $[5,6]$ when given poisson-distributed random input spike trains $[1,2,4,7-9]$. While unimodal weight distributions have been observed as an outcome in some in vitro experiments [5], the actual biochemical process that changes synaptic connection strengths has yet to be fully understood.

Unfortunately, attractor-based STDP has been repeatedly shown to be computationally less powerful than attractor-less STDP [9] and successful implementations of attractor-based STDP used attractors that were either very weak [8] or very close to some minimum weight $[2,3]$, causing a more "additive-like" $[2,8]$ behaviour of the plasticity rule. We therefore examined possible biological interpretations of attractor-less STDP rules while keeping in mind that any STDP rule is just an abstraction from the hidden biophysical reality.

We show how unimodal weight distributions can reliably result from attractor-less STDP when negative synaptic drift is combined with activity-independent synaptic growth. A bimodal distribution is then only formed when non-random (polychromous [10]) poissondistributed inputs are presented to a neuron [11]. In practice, this produces a plasticity rule that keeps the postsynaptic neuron unselective and responsive to a broad range of inputs while receiving only random spikes, but quickly allows the neuron's receptive field to become highly selective as soon as some inputs start repeating a non-random ordering of spikes.

This stabilization procedure preserves STDP's sensitivity to temporally shifted correlations in input spike data, which in turn gives us several beneficial features for biologically more realistic and computationally more powerful [12] implementations of plasticity in spiking neural networks.

\section{Authors' details \\ ${ }^{1}$ BrainLinks-BrainTools, University of Freiburg, Freiburg im Brisgau, Germany. \\ ${ }^{2}$ Neuroelectronic Systems, University Medical Center Freiburg, Freiburg im} Brisgau, Germany.

Published: 18 December 2015

\section{References}

1. Rubin J, Lee D, Sompolinsky H: Equilibrium Properties of Temporally Asymmetric Hebbian Plasticity. Phys Rev Lett 2001, 86(2):364-367, doi:10.1103/PhysRevLett.86.364.

2. Gütig R, Aharonov R, Rotter S, Sompolinsky H: Learning input correlations through nonlinear temporally asymmetric Hebbian plasticity. J Neurosci 2003, 23(9):3697-3714.

3. Morrison A, Aertsen A, Diesmann M: Spike-timing-dependent plasticity in balanced random networks. Neural Comput 2007, 19(6):1437-1467, doi:10.1162/neco.2007.19.6.1437.

4. van Rossum MCW, Bi GQ, Turrigiano GG: Stable Hebbian learning from spike timing-dependent plasticity. J Neurosci 2000, 20(23):8812-8821.

5. Turrigiano GG, Leslie KR, Desai NS, Rutherford LC, Nelson SB: Activitydependent scaling of quantal amplitude in neocortical neurons. Nature 1998, 391(6670):892-896, doi:10.1038/36103.

6. Turrigiano GG, Nelson SB: Homeostatic plasticity in the developing nervous system. Nat Rev Neurosci 2004, 5(2):97-107, doi:10.1038/nrn1327.

7. Sjöström PJ, Turrigiano GG, Nelson SB: Rate, timing, and cooperativity jointly determine cortical synaptic plasticity. Neuron 2001, 32(6):1149-1164.

8. Gilson M, Burkitt AN, Grayden DB, Thomas Da, van Hemmen JL: Emergence of network structure due to [STDP] in recurrent neuronal networks $\mathrm{V}$ : self-organization schemes and weight dependence. Biol Cybern 2010, 103(5):365-386.

9. Billings $G$, van Rossum MCW: Memory retention and spike-timingdependent plasticity. J Neurophysiol 2009, 101(6):2775-2788, doi:10.1152/ jn.91007.2008.

10. Izhikevich EM: Polychronization: computation with spikes. Neural Comput 2006, 18(2):245-282.

11. Guyonneau R, VanRullen R, Thorpe SJ: Neurons tune to the earliest spikes through STDP. Neural Comput 2005, 17(4):859-879, doi:10.1162/ 0899766053429390.

\footnotetext{
* Correspondence: simon.vogt@blbt.uni-freiburg.de

1 BrainLinks-BrainTools, University of Freiburg, Freiburg im Brisgau, Germany

Full list of author information is available at the end of the article
} 
12. Olshausen BA, Field DJ: Emergence of simple-cell receptive field properties by learning a sparse code for natural images. Nature 1996 381(6583):607-609, doi:10.1038/381607a0.

doi:10.1186/1471-2202-16-S1-P103

Cite this article as: Vogt and Hofmann: Balancing the critical period of spiking neurons with attractor-less STDP. BMC Neuroscience 2015

16(Suppl 1):P103.

Submit your next manuscript to BioMed Central and take full advantage of:

- Convenient online submission

- Thorough peer review

- No space constraints or color figure charges

- Immediate publication on acceptance

- Inclusion in PubMed, CAS, Scopus and Google Scholar

- Research which is freely available for redistribution

Submit your manuscript at www.biomedcentral.com/submit 